\title{
Analisis Bantuan Traktor dalam Meningkatka Pendapatan Petani di Kecamatan Ponrang Selatan Kanbupaten Luwu
}

\author{
Husmaruddin ${ }^{1}$ \\ Salma $^{2}$ \\ No. HP $085340715411^{1}, 081342701659^{2}$ \\ ${ }^{1}$ Alamat Korespondensi: \\ Email: husmaruddin@ymail.com
}

\begin{abstract}
Abstrak
Penelitian ini bertujuan untuk menganalisis apaka bantuan traktor dapat meningkatkan pendapatan petani yang ada di Kecamatan Ponrang Selatan Kabupaten Luwu. Adapun masalah dalam penelitian ini yaitu apakah bantuan traktor dapat meningkatkan pendapatan Petani yang ada di Kecamatan Ponrang Selatan Kabupaten Luwu. Pembahasan dalam penelitian ini adalah Peranan Pemerintah dalam memberikan bantuan kepada petani, pengertian Traktor, Pengertian Pendapatan,Produksi dan teori Pendapatan, tujuan penelitian ini untuk mengetahui apaka bantuan traktor dapat meningkatkan pendapatan petani.

Analisis tersebut dilakukan dengan mengunakan metode penelitian Kualitatif. Dengan menggunakan rumus Analisis Regresi Sederhana dimana

$$
\begin{aligned}
& Y=a+b x \\
& Y=3,634+2.139 X
\end{aligned}
$$

Hasil analisis mendapatkan bahwa bantuan traktor memiliki pengaruh positif atau siknifikan terhadap pendapatan petani yang ada di Kecamatan Ponrang Selatan Kabupaten Luwu.
\end{abstract}

\section{Kata Kunci : Bantuan Traktor, Pendapatan Petani, tujuan penelitian,hasil analisis.}

\section{Pendahuluan}

Indonesia merupakan negara agraris, dimana sebagian besar masyarakatnya hidup dari bercocok tanam. Oleh karena itu, pembangunan sektor pertanian merupakan sektor penggerak perkembangan ekonomi dan laju pertumbuhan ekonomi. Dalam hal ini sektor pertanian masih merupakan salah satu sektor tumpuan yang diharapkan dalam proses pertumbuhannya dapat memenuhi kebutuhan konsumsi masyarakat yang cenderung meningkat.

Sektor pertanian merupakan sektor yang mendapatkan perhatian cukup besar dari pemerintah dikarenakan peranannya yang sangat penting dalam rangka pembangunan ekonomi jangka panjang maupun dalam rangka pemulihan ekonomi bangsa. Peranan sektor pertanian adalah sebagai sumber penghasil bahan kebutuhan pokok, sandang dan papan, menyediakan lapangan kerja bagi sebagian besar penduduk, memberikan sumbangan terhadap pendapatan nasional yang tinggi, memberikan devisa bagi negara dan mempunyai efek pengganda ekonomi yang tinggi dengan rendahnya ketergantungan terhadap impor (multiplier effect), yaitu keterkaitan input-output antar industri, konsumsi dan investasi. Dampak pengganda tersebut relatif besar, sehingga sektor pertanian layak dijadikan sebagai sektor andalan dalam pembangunan ekonomi nasional. Sektor pertanian juga dapat menjadi basis dalam mengembangkan kegiatan ekonomi perdesaan melalui pengembangan usaha berbasis pertanian yaitu agribisnis dan agroindustri. Dengan pertumbuhan yang terus positif secara konsisten, 
sektor pertanian berperan besar dalam menjaga laju pertumbuhan ekonomi nasional.

Hal ini ditunjukan dari banyaknya penduduk atau tenaga kerja yang hidup atau bekerja pada sektor pertanian serta produk nasional yang berasal dari pertanian, artinya pertanian memegang peranan penting dari keseluruhan perekonomian nasional.

$$
\text { A.T Mosher }(1989 ; 19) \text { mengartikan }
$$
pertanian adalah sejenis proses produksi khas yang didasarkan atas proses pertumbuhan tanaman dan hewan. Kegiatan-kegiatan produksi didalam setiap usaha tani merupakan suatu bagian usaha, dimana biaya dan penerimaan adalah penting. Tumbuhan merupakan pabrik pertanian yang primer.

Pertanian merupakan sektor yang sangat penting dalam perekonomian nasional. Oleh karena itu, pembangunan ekonomi nasional abad 21 masih akan tetap berbasis pertanian secara luas. Tanaman padi sebagai penghasil beras merupakan sumber makanan pokok sebagian besar penduduk Indonesia dan menjadi komoditas strategis secara ekonomi.

Kemajuan dan pembangunan dalam bidang apapun tidak dapat dilepaskan dari kemajuan teknologi. Revolusi pertanian didorong oleh penemuan mesin-mesin dan cara-cara baru dalam bidang pertanian. A.T Mosher (1989;235) menganggap teknologi yang senantiasa berubah itu sebagai syarat mutlak adanya pembangunan pertanian.

Apabila tidak ada perubahan dalam teknologi maka pembangunan pertanian pun terhenti. Produksi terhenti kenaikannya, bahkan dapat menurun karena merosotnya kesuburan tanah atau karena kerusakan yang makin meningkat olehhamapenyakit yang semakin merajalela.

Traktor pertanian saat ini menjadi komponen yang tak terpisahkan dari pembangunan pertanian dan pedesaan. Kita sakasikan perkembangan yang pesat penggunaan traktor tangan di pedesaan. Kita saksikan bahwa jarang penduduk yang telah merasakan manfaat penggunaan traktor untuk melakukan pekerjaan pengolahan tanah secara cepat kemudian beralih memilih menggunakan hewan atau tenaga otot untuk pekerjaan yang sama. Hal tersebut karena mereka dapat memperbandingkan bahwa ternyata melakukan pengolahan tanah dengan traktor lebih menguntungkan dibanding cara lain.

Pada saat ini traktor digunakan untuk berbagai keperluan. Penggunaan yang paling banyak ialah untuk pengolahan tanah, karena memang pekerjaan pengolahan tanah adalah pekerjaan pertanian yang relatif membutuhkan daya yang besar dibanding pekerjaan lainnya. Selain itu traktor juga digunakan untuk penanaman, untuk pemeliharan tanaman, untuk memutar pompa irigasi, untuk pemanen (dengan memasang pisau reaper), untuk memutar perontok padi, serta untuk pengangkutan, mulai dari bibit, pupuk, peralatan, sampai hasil pertanian.

Dalam meningkatka produksi pertanian terutama bagi usahatani yang tergantung pada musim. Kelangkaan tenaga kerja berakibat mundurnya penanaman sehigga berpengaruh pada pertumbuhan tanaman, produktivitas, dan kualitas produk. Sehingga peranan petani sagatlah penting dalam meningkatkan produksi pertanian terutama padi. 


\section{Metode Penelitian}

Peneliti mengambil tempat di Kecamatan Ponrang Selatan Kabuapten Luwu karena Selain dekat dari tempat peneli juga kebanyakan masyarakatnya bertani. Dalam melakukan penelitian, data yang dikumpulkan akan digunakan untuk memecahkan masalah yang ada sehingga data-data tersebut harus benar- benar dapat dipercaya dan akurat. Data yang digunakan dalam penelitian ini diperoleh melalui wawancara secara langsung kepada Petani yang mendapatkan bantuan traktor di Kecamatan Ponrang Selatan Kabupaten Luwu dari Tahun 2009 samapai Tahun 2013. Kegiatan mengumpulkan bahan-bahan yang berkaitan dengan penelitian yang berasal dari jurnal-jurnal ilmiah, literatur-literatur serta publikasi-publikasi lain yang layak dijadikan sumber.

Kegiatan menganalisis data dalam penelitian ini meliputi beberapa tahap dasar (Santoso dan Tjiptono, 2001), tahap tersebut diantaranya: Proses editing, Tahap awal analisis data adalah melakukan edit terhadap data yang telah dikumpulkan dari hasil survey di lapangan. Pada prinsipnya proses editing data bertujuan agar data yang nanti akan dianalisis telah akurat dan lengkap. Proses Coding, Proses pengubahan data kualitatif menjadi angka dengan mengklasifikasikan jawaban yang ada menurut kategori-kategori yang penting. Tabulasi, Menyajikan data-data yang diperoleh dalam tabel, sehingga diharapkan pembaca dapat melihat hasil penelitian dengan jelas. Setelah proses tabulasi selesai kemudian data-data dalam tabel tersebut akan diolah dengan bantuansoftware statistik yaitu SPSS.

Jenis dan sumber data yang digunakan yaitu Data primer adalah data yang dikumpulkan dan diolah sendiri oleh suatu organisasi atau perorangan langsung dari objeknya. Dalam penelitian ini, data primer diperoleh dari jawaban responden yang disebar melalui responden. Data sekunder merupakan data yang diperoleh secara tidak langsung dari petani yang ada di Kecamatan Ponrang Selatan Kabupaten Luwu dalam bentuk literatur yang ada di buku-buku yang ada hubungannya dengan penelitian ini.

\section{Metode Analisis Data}

Analisis untuk mengetahui pengaruh Bantuan Traktor dalam Meningkatkan Produksi Pertanian di Kecamatan Ponrang Selatan Kabupaten Luwu.

1. Analisis Regresi Sederhana

Regresi linier sederhana adalah hubungan secara linear dan pengaruh antara satu variabel independen $(\mathrm{X})$ dengan variabel dependen $(\mathrm{Y})$. Analisis ini untuk mengetahui arah hubungan antara variabel independen dengan variabel dependen apakah positif atau negatif dan untuk memprediksi nilai dari variabel dependen apabila nilai variabel independen mengalami kenaikan atau penurunan. Data yang digunakan biasanya berskala interval atau rasio.( Ghozali 2001)

$\mathrm{Y}=\mathrm{a}+\mathrm{bx}$

Dimana:

$\mathrm{Y}=$ Pendapatan Petani

$\mathrm{a}=$ Konstanta

$\mathrm{X}=$ Bantuan Traktor 
$\mathrm{b}=$ Koefisien regresi yaitu besarnya perubahan yang terjadi pada $\mathrm{Y}$ jika satu unit perubahan pada variabel sederhana (variabel $\mathrm{x}$ )

2. Koefisien Determinasi

Koefisien determinasi $\left(\mathrm{R}^{\mathbf{2}}\right)$ pada intinya mengukur seberapa jauh kemampuan model dalam menerangkan variasi variabel dependen. Nilai koefisien determinasi adalah antara nol dan satu. Nilai $\mathrm{R}^{2}$ yang kecil berarti kemampuan variabel variabel independen dalam menjelaskan variasi variabel dependen amat terbatas. Nilai yang mendekati satu berarti variabel-variabel independen memberikan hampir semua informasi yang dibutuhkan untuk memprediksi variasi variabel dependen.

\section{Hasil Penelitian dan Pembahasan}

\section{Gambaran umum responden yang mendapatkan bantuan traktor}

Seperti yang terlihat pada tabel 1, para responden yang mendaptkan bantuan traktor dari Pemerintah Daerah Kabupaten Luwu dari Tahun 2009 sampai 2013, Hal ini terlihat dari data Tabel 1.

Tabel 1: Resopnden yang mendapatkan bantuan Traktor

\begin{tabular}{|c|c|}
\hline Tahun & Orang \\
\hline 2009 & 7 \\
\hline 2010 & 8 \\
\hline 2011 & 12 \\
\hline 2012 & 24 \\
\hline 2013 & 15 \\
\hline Jumlah & 66 \\
\hline
\end{tabular}

Sumber : Dinas Petanian Kab.Luwu, 2014
Tabel 1 menunjukkan jumlah sampel yang diambil dari tahun 2009 sampai 2013. Jumlah sampel tersebut diambil secara objektif dengan jumlah yang proposional untuk mewakili seluruh populasi penelitian.

\section{Gambaran umum responden}

Berdasarkan hasil penelitian, diperoleh gambaran tentang besar pendapatan rata rata petani tahun 2009.

Tabel 2: Pendapatan Petani Yang Mendapatkan Bantuan Traktor Hanun 2009

\begin{tabular}{|l|l|l|l|}
\hline No & \multicolumn{1}{|c|}{$\begin{array}{c}\text { Nana } \\
\text { Responden }\end{array}$} & \multicolumn{1}{|c|}{$\begin{array}{c}\text { Pendapatan } \\
\text { Petani }\end{array}$} & $\begin{array}{c}\text { Luas } \\
\text { Lahan }\end{array}$ \\
\hline 1 & Said & Rp. 7.125.000,- & $1 \mathrm{H}$ \\
\hline 2 & A. Ampanaggi & Rp. 15.437.500,- & $2 \mathrm{H}$ \\
\hline 3 & Makmur & Rp. 7.362.500,- & $1 \mathrm{H}$ \\
\hline 4. & Rasbi & Rp. 10.925.000,- & $1 \frac{112 \mathrm{H}}{}$ \\
\hline 5. & Rusman & Rp. 7.600.000,- & $1 \mathrm{H}$ \\
\hline 6. & Bahri Samad & Rp. 7.275.000,- & $1 \mathrm{H}$ \\
\hline 7. & Masmuddin & Rp. 10.800.000,- & $1 \frac{1 / 2 \mathrm{H}}{2}$ \\
\hline J u m I a h & Rp. 66.525.000,- & $\mathbf{9 ~ H}$ \\
\hline
\end{tabular}

Sumber, Data yang diolah, 2014

Tabel 2 menjukan pendapatan petani tahun 2009 dengal luasa lahan $9 \mathrm{H}$ dengan pendapatan Rp. 66.525.000,-. Untuk memepermuda pengolaan data peneliti mengambil nilai rata rata pendapatan petani tahun 2009 dengan cara Pendapatan petani di bagi dengan jumlah petani yang mendapatakan bantuan. Rp 66.525.000/7 = Rp. 9.503.571,-. Jadi peneliti mengambil data rata rata pendapatan petani yaitu : Rp. 9.503.571. 
Tabel 3: Pendapatan Petani Yang Mendapatkan Bantuan Traktor Tahun 2010

\begin{tabular}{|l|l|l|l|}
\hline No & \multicolumn{1}{|c|}{$\begin{array}{c}\text { Nama } \\
\text { Resopnden }\end{array}$} & \multicolumn{1}{|c|}{$\begin{array}{c}\text { Pendapatan } \\
\text { Petani }\end{array}$} & \multicolumn{1}{c|}{$\begin{array}{c}\text { Luas } \\
\text { Lahan }\end{array}$} \\
\hline 1. & Saharuddin & Rp. 15.762.500,- & $2 \mathrm{H}$ \\
\hline 2. & $\begin{array}{l}\text { Adam } \\
\text { Nasrum }\end{array}$ & Rp. 18.287.500,- & $21 / 2 \mathrm{H}$ \\
\hline 3. & Pudding & Rp.7.350.000,- & $1 \mathrm{H}$ \\
\hline 4. & Kaswadi & Rp.7.517.500,- & $1 \mathrm{H}$ \\
\hline 5. & Supirman & Rp.10.687.500,- & $1 \mathrm{1} / 2 \mathrm{H}$ \\
\hline 6. & Andi Asmadi & Rp.7.440.000,- & $1 \mathrm{H}$ \\
\hline 7. & Hisman & Rp.15.680.000,- & $2 \mathrm{H}$ \\
\hline 8. & Darlis & Rp.7.680.000,- & $1 \mathrm{H}$ \\
\hline J u m l a h & Rp.90.404.500,- & $12 \mathrm{H}$ \\
\hline
\end{tabular}

Sumber, Data yang diolah, 2014

Tabel 3 Menujukan pendapatan petani yang mendapatkan bantuan traktor tahun 2010 luas lahan 12 H dengan pendapatan Rp. 90.404.500,-. Peneliti mengambil nilai rata rata dari pendapatan total petani di bagi dengan petani petani yang mendapatkan bantuan tahun 2010. Rp. 90.404.500,-/8 = Rp.11.300.563,-

Tabel 4: Pendapatan Petani Yang Mendapatkan Bantuan Traktor Tahun 2011

\begin{tabular}{|c|c|c|c|}
\hline No & $\begin{array}{l}\text { Nama } \\
\text { Resopnden }\end{array}$ & $\begin{array}{l}\text { Pendapatan } \\
\text { petani }\end{array}$ & $\begin{array}{l}\text { Luas } \\
\text { Lahan }\end{array}$ \\
\hline 1. & Mas'ud & Rp. 8.730.000,- & $1 \mathrm{H}$ \\
\hline 2. & H. Ardin & $\operatorname{Rp} .9 .216 .000,-$ & $1 \mathrm{H}$ \\
\hline 3. & Irwan & Rp.18.711.000,- & $2 \mathrm{H}$ \\
\hline 4. & Akir & Rp. 9.207.000,- & $1 \mathrm{H}$ \\
\hline 5. & Mahmuddin & Rp.12.804.000,- & $11 / 2 \mathrm{H}$ \\
\hline 6. & Rais & Rp.19.296.000,- & $2 \mathrm{H}$ \\
\hline 7. & Lotong & Rp.22.515.000,- & $2 \mathrm{H}$ \\
\hline 8. & Jamaluddin & Rp.27.360.000,- & $3 \mathrm{H}$ \\
\hline 9. & Yasmin & Rp. 9.504.000,- & $1 \mathrm{H}$ \\
\hline 10. & Aswadi K & Rp.19.665.000,- & $2 \mathrm{H}$ \\
\hline 11 & Sikir Sangga & Rp. 9.405.000,- & $1 \mathrm{H}$ \\
\hline 12. & A. Asmadi & Rp.13.667.000,- & $11 / 2 \mathrm{H}$ \\
\hline \multicolumn{2}{|c|}{ J u m la h } & Rp.180.090.000,- & $19 \mathrm{H}$ \\
\hline
\end{tabular}

Sumber, Data yang diolah, 2014
Tabel 4 menunjukan jumlah pendapatan petani tahun 2011 dengan luas lahan $19 \mathrm{H}$ dengan pendapatan Rp. $180.000 .000,-. \quad$ Untuk mempermuda proses perhitungan maka peneliti hanya mengambil data dengan perhitungan rata rata dimana jumlah pendapatan di bagi dengan Petani yang mendapatkan bantuan traktor yaitu : Rp. 180.000.000,- / 12 Bantuan = Rp. 15.007.500,Pendapatan Rata rata Petani.

Tabel 5 Pendapatan Petani Yang Mendapatkan Bantuan Traktor Tahun 2012

\begin{tabular}{|c|c|c|c|}
\hline No & Nama Responden & $\begin{array}{c}\text { Pendapatan } \\
\text { Petani }\end{array}$ & $\begin{array}{c}\text { Luas } \\
\text { Lahan }\end{array}$ \\
\hline 1. & H. Andi Baso Aca & Rp. 12.825.000,-- & $11 / 2 \mathrm{H}$ \\
\hline 2. & Sudarmin & Rp. 9.690.000,- & $1 \mathrm{H}$ \\
\hline 3. & A. Asri & Rp. 25.602.500,- & $21 / 2 \mathrm{H}$ \\
\hline 4. & Syahrir & Rp. 17.280.000,- & $2 \mathrm{H}$ \\
\hline 5. & Abd. Rahman & Rp. $8.820 .000,-$ & $1 \mathrm{H}$ \\
\hline 6. & Sabaruddin & Rp. $9.504 .000,-$ & $1 \mathrm{H}$ \\
\hline 7. & Manda & Rp. 18.810.000,- & $2 \mathrm{H}$ \\
\hline 8. & Takka & Rp. 26.496.000,-- & $3 \mathrm{H}$ \\
\hline 9. & Gaffar & Rp. 12.960.000,- & $11 / 2 \mathrm{H}$ \\
\hline 10. & Suryadi & Rp. 19.008.000,- & $2 \mathrm{H}$ \\
\hline 11. & Arifin & Rp. $8.640 .000,-$ & $1 \mathrm{H}$ \\
\hline 12. & Herman & Rp. 9.114.000,- & $1 \mathrm{H}$ \\
\hline 13. & Kasim & Rp. 18.780.000,- & $2 \mathrm{H}$ \\
\hline 14. & Khairil Anwar & Rp. 18.624.000,-- & $2 \mathrm{H}$ \\
\hline 15. & Samsuddin & Rp. 13.818.000,- & $21 / 2 \mathrm{H}$ \\
\hline 16. & Sahib & Rp. 18.624.000,- & $2 \mathrm{H}$ \\
\hline 17. & Rudi Salam & Rp. 28.224.000,- & $3 \mathrm{H}$ \\
\hline 18. & Akir & Rp. 18.432.000,- & $2 \mathrm{H}$ \\
\hline 19. & Baharuddin & Rp. $8.550 .000,-$ & $1 \mathrm{H}$ \\
\hline 20. & Lundi & Rp. $9.504 .000,-$ & $1 \mathrm{H}$ \\
\hline 21. & Manddanuang & Rp. 27.072.000,-- & $3 \mathrm{H}$ \\
\hline 22. & Abd. Rasyid & Rp. 22.464.000,-- & $21 / 2 \mathrm{H}$ \\
\hline 23. & Basmin & Rp. 12.384.000,-- & $11 / 2 \mathrm{H}$ \\
\hline 24. & Musliadi & Rp. 9.306.000,-- & $1 \mathrm{H}$ \\
\hline \multicolumn{2}{|c|}{ Total } & Rp. 383.471,500,- & $43 \mathrm{H}$ \\
\hline
\end{tabular}

Tabel 5 menunjukan jumlah pendapatan petani pada tahun 2012 dengan luas lahan $43 \mathrm{H}$ dengan nilai pendapatan Rp.383.471.500,-.Nilai 
rata rata pendapatan dibagi dengan bantuan trktor sama dengan Rp.16.019.646,-.

Tabel 6: Pendapatan Petani Yang Mendapatkan Bantuan Traktor Tahun 2013

\begin{tabular}{|c|c|c|c|}
\hline No & $\begin{array}{c}\text { Nama } \\
\text { Responden }\end{array}$ & $\begin{array}{c}\text { Pendapatan } \\
\text { Petani }\end{array}$ & $\begin{array}{c}\text { Luas } \\
\text { Lahan }\end{array}$ \\
\hline 1. & Muh. Ikbal & Rp. 21.612.500,- & $2 \mathrm{H}$ \\
\hline 2. & Supriadi & Rp. 21.840.000,- & $2 \mathrm{H}$ \\
\hline 3. & Rusbi & Rp. 10.185.000,- & $1 \mathrm{H}$ \\
\hline 4. & Muh. Syaid & Rp. 14.962.500,- & $11 / 2 \mathrm{H}$ \\
\hline 5. & Rudi & Rp. $9.975 .000,-$ & $1 \mathrm{H}$ \\
\hline 6. & Iskandar & Rp. 10.972.500,- & $1 \mathrm{H}$ \\
\hline 7. & Nasaruddin & Rp. 29.905.000,- & $3 \mathrm{H}$ \\
\hline 8. & Roysman & Rp. 30.240.000,- & $3 \mathrm{H}$ \\
\hline 9. & Afgoni & Rp. 25.872.000,- & $21 / 2 \mathrm{H}$ \\
\hline 10. & Hamja & Rp. 15.120.000,- & $2 \mathrm{H}$ \\
\hline 11. & Sukrianto & Rp. 10.640.000,- & $1 \mathrm{H}$ \\
\hline 12. & Hamriadi & Rp. 10.416.000,- & $1 \mathrm{H}$ \\
\hline 13. & Rusdi & Rp. 15.295.000,- & $11 / 2 \mathrm{H}$ \\
\hline 14. & Ruslan & Rp. 15.627.500,- & $2 \mathrm{H}$ \\
\hline 15. & Anthon & Rp. 10.752.000,- & $1 \mathrm{H}$ \\
\hline \multicolumn{2}{|c|}{ Tota 1} & Rp.253.435.000,- & $251 / 2 \mathrm{H}$ \\
\hline
\end{tabular}

Sumber, data yang diolah, 2014

Tabel 6 menujukan bahwa pendapatan petani tahu 2013, luas lahan 25 1/2 $\mathrm{H}$ dengan jumlah pendapatan sebesar Rp.253.435.000,- Nilai rata rata petani yaitu pendapatan di bagi dengan jumlah bantuan traktor sama dengan Rp.16.895.666,-

Tabel 7: Pengaruh Bantuan Traktor Terhadap Pendapatan Petani Yang Mendapatkan Bantuan

\begin{tabular}{|c|c|c|}
\hline Tahun & $\begin{array}{c}\text { Yang } \\
\text { Mendapatkan } \\
\text { Bantuan Traktor } \\
\text { (X) }\end{array}$ & $\begin{array}{c}\text { Pendapatan } \\
\text { Petani (Y) }\end{array}$ \\
\hline 2009 & 7 & Rp. 9.503.571,- \\
\hline 2010 & 8 & Rp. 11.300.563,- \\
\hline 2011 & 12 & Rp. 15.007.500,- \\
\hline 2012 & 24 & Rp. 16.019.646,- \\
\hline 2013 & 15 & Rp. 16.895.667,- \\
\hline 5 & 66 & Rp. 68.726.947,- \\
\hline
\end{tabular}

Sumber : data yang diolah, 2014
Tabel 7 menujukan nilai pendapatan rata rata petani yang menerima bantuan traktor di Kecamatan Ponrang Selatan Kabupaten Luwu Mulai dari tahun 2009 sampai dengan tahun 2013

\section{Pembahasan}

\section{Analisis Data Regresi Sederhana}

Analisis regresi linear berganda sederhana digunakan dalam penelitian ini dengan tujuan untuk mengetahui ada tidaknya pengaruh variabel bebas terhadap variabel terikat. Perhitungan statistik dalam analisis regresi linear Sederhana yang digunakan dalam penelitian ini adalah dengan menggunakan bantuan program komputer SPSS for Windows versi 15.0. Ringkasan hasil pengolahan data dengan menggunakan program SPSS tersebut adalah sebagai berikut : (Ghozali 2001). 
Tabel 8: Coefficients (a)

\begin{tabular}{|c|c|c|c|c|c|}
\hline \multirow[t]{2}{*}{ Model } & \multicolumn{2}{|c|}{ Unstandardized Coefficients } & $\begin{array}{c}\text { Standardized } \\
\text { Coefficients }\end{array}$ & $\mathbf{t}$ & Sig. \\
\hline & B & Std. Error & Beta & B & Std. Error \\
\hline $\begin{array}{l}\text { (Constant) } \\
\text { Bantuan Traktor }\end{array}$ & $\begin{array}{l}8959307,493 \\
362581,948\end{array}$ & $\begin{array}{l}2465734,273 \\
169507,313\end{array}$ & ,777 & $\begin{array}{l}3,634 \\
2,139\end{array}$ & $\begin{array}{l}, 036 \\
, 122\end{array}$ \\
\hline
\end{tabular}

a Dependent Variable: Pendapatan Petani

Dari hasil tersebut apabila ditulis dalam bentuk standardized dari persamaan regresinya adalah sebagai berikut :

$\mathrm{Y}=\mathrm{a}+\mathrm{bx}$

$\mathrm{Y}=8959307,493+362581,948 \mathrm{X}$

Karna Nilai Koefisien $b=362581,948$ maka model regesinya bernilai fositif atau searah yang artinya setiap ada penambahan 1 unit baruan

Tabel 9: Model Summary (b)

\begin{tabular}{|l|l|l|l|l|}
\hline \multicolumn{1}{|c|}{ Model } & \multicolumn{1}{|c|}{ R } & \multicolumn{1}{|c|}{ R Square } & Adjusted R Square & Std. Error of the Estimate \\
\hline 1 &, $777(\mathrm{a})$ &, 604 &, 472 & 2316737,75390 \\
\hline
\end{tabular}

a Predictors: (Constant), Bantuan Traktor

b Dependent Variable: Pendapatan Petani

$$
\mathrm{R}=0,777 \text { berada di antra nilai } 0,604-
$$
1,000 dapat di simpulkan bahwa antara bantuan traktor $(\mathrm{X})$ dengan pendapatan petani (Y) sangant kuat.

Hasil perhitungan dengan menggunakan program SPSS versi 15 dapat diketahui bahwa koefisien determinasi (Squere R2) yang diperoleh sebesar 0,604. Hal ini berarti 60,4\% Bantuan Traktor dapat dijelaskan oleh variabel pendapatan, sedangkan sisanya yaitu 39,6\% dipengaruhi oleh variabel-variabel lainnya yang tidak diteliti dalam penelitian ini, seperti penggunaan pupuk,BBM, racun, sewah buruh dari petani yang tidak mendapatkan batuan traktor. traktor maka meningkatpulah pendapatan petani sebesar Rp. 362,581,948

\section{Koefisien Determinasi $\left(\mathbf{R}^{2}\right)$}

Koefisien determinasi (R2 ) pada intinya mengukur seberapa jauh kemampuan model dalam menerangkan variasi variabel dependen. Nilai koefisien determinasi adalah antara nol dan satu (Ghozali, 2001). 
jangka panjang maupun dalam rangka pemulihan ekonomi bangsa. Peranan sektor pertanian adalah sebagai sumber penghasil bahan kebutuhan pokok, sandang dan papan.

Pertanian adalah sejenis proses produksi khas yang didasarkan atas proses pertumbuhan tanaman dan hewan. Kegiatan-kegiatan produksi didalam setiap usaha tani merupakan suatu bagian usaha, dimana biaya dan penerimaan adalah penting. Tumbuhan merupakan pabrik pertanian yang primer.

Traktor adalah kendaraan yang didesain secara spesifik untuk keperluan traksi tinggi pada kecepatan rendah, atau untuk menarik trailer atau instrumen yang digunakan dalam pertanian atau konstruksi. Istilah ini umum digunakan untuk mendefinisikan suatu jenis kendaraan untuk pertanian. Instrumen pertanian umumnya digerakkan dengan menggunakan kendaraan ini, ditarik ataupun didorong, dan menjadi sumber utama mekanisasi pertanian.

Produksi adalah usaha menciptakan dan meningkatkan kegunaan suatu barang untuk memenuhi kebutuhan. Dalam kegiatan usahatani selalu diperlukan faktor-faktor produksi berupa lahan, tenaga kerja, dan modal yang dikelola seefektif dan seefisien mungkin sehingga memberikan manfaat sebaik-baiknya.

Sektor pertanian diIndonesia dianggap penting terlebih dari peranan sektor pertanian terhadap penyediaan lapangan kerja, penyediaan pangan, penyumbang devisa negara melalui ekspor dan sebagainya. Dalam pertanian tanaman pangan diIndonesia terdapat urutan komoditas menurut kepentingannya (Badan Penelitian dan Pengembangan Departemen Pertanian, 1990;8).
Tanaman padi adalah tanaman utama. Meskipun secara ekonomis tanaman padi bukan yang paling menguntungkan, kebanyakan petani mengutamakan padi dalam usaha taninya.

Menurut Hernanto (1994), besarnya pendapatan yang akan diperoleh dari suatu kegiatan usahatani tergantung dari beberapa faktor yang mempengaruhinya seperti luas lahan, tingkat produksi, identitas pengusaha, pertanaman, dan efisiensi penggunaan tenaga kerja. Dalam melakukan kegiatan usahatani, petani berharap dapat meningkatkan pendapatannya sehingga kebutuhan hidup sehari-hari dapat terpenuhi.

Efisiensi merupakan hasil perbandingan antara output fisik dan input fisik. Semakin tinggi rasio output terhadap input maka semakin tinggi tingkat efisiensi yang dicapai. Efisiensi juga dapat dijelaskan sebagai pencapaian output maksimum dari penggunaan sumber daya tertentu. Jika output yang dihasilkan lebih besar dari pada sumber daya yang digunakan maka semakin tinggi pula tingkat efisiensi yang dicapai.

Teori Efisiensi adalah suatu ukuran dari ketetapan sasaran dari suatu proses / kegiatan yang dilakukan.

Berdasarkan pada hasil analisis regresi sederhana yang telah dilakukan pada penelitian ini, didapat persamaan regresi sebagai berikut :

$\mathrm{Y}=\mathrm{a}+\mathrm{bx}$

$Y=8959307,493+362581,948 X$

Hipotesisnya : ada pengaruh yang siknifikan antara bantuan traktor dan pendapatan petani yang ada di Kecamatan Ponrang Selatan Kabupaten Luwu. Dimana setiap ada penambahan 1 unit bantuan traktor makan pendapatan petani meningkat sebesar Rp.362,581,948 


\section{Saran}

Bagi petani yang suda mendapatkan bantuan traktor dapat memanfaatkannya dengan baik sehingga hasil peningkatkan hasil produksinya dengan baik sehingga dapat mesejahterakan keluarganya.

Bagi pemerintah di Daerah Kabupaten Luwu jangan cuman kolompok tani saja yang diutaman untuk diberikan Bantuan Traktor Tapi cobalah untuk melihat petani yang tidak mempunyai lahan yang cukup luas untuk diberikan bantuan traktor, kenapa demikian karna kebanyakan yang dilihat dari lapangan petani yang mendaptkan bantuan traktor itu dari kalangan yang lebih berada sedangkan petani yang kurang berada harus mengeluarka biaya sewa traktor di mana setip tahun sewanya mengalami kenaikan.

Peneliti sagat sulit untuk bertemu langsung dengan petani di rumah sehingga peneliti harus turung langsung kelapangan

\section{Daftar Pustaka}

Ferdinand, Augusty T.,2006. Metode Penelitian: Pedoman Penelitian untuk Penulisan Skripsi, Tesis dan Desertasi, BP Undip, Semarang.

Ghozali, Imam. 2001. Aplikasi Analisis Multivariate dengan Program SPSS, BP UNDIP, Semarang.

Hasan Basri Tarmizi dan GunawanSumodiningrat. 1989. Pengaruh Penggunaan Faktor Produksi Terhadap Produksi, Pendapatan dan Distribusinya Pada Sawah Berpengairan danTanpa Pengairan, Berkala Penelitian Pasca SarjanaUniversitas Gadjah Mada (BPPSUGM), Jilit 2,No.2A, Edisi 1989. hlm 359-375.

Kasryno, Faisal. 1996. Meningkatkan Pemanfaatan Sumber Daya Pertanian dan
Pengembangan Sistem Usaha Pertanian Menuju Era Globalisasi Ekonomi, Litbang Pertanian, Jakarta.

Mubyarto. 1994. Pengantar Ekonomi Pertanian. LP3ES. Jakarta.

Salma 2014

http://paskomnas.com/id/berita/Kondisi

Pertanian Indonesia saat ini Berdasarkan Pandangan Mahasiswa Pertanian Indonesia. php

Suratiyah, K. 2006. Ilmu Usahatani. Penebar Swadaya. Jakarta.

Soekartawi, A. S., L. D. Jhon dan J. B. Hardaker. 1986. Ilmu Usahatani dan Traktor.

Salma. 2014 alat dan mesin pertanian, (Htt://www.mb.ipb.ac.id ) Diakses 06 Januari 2014-02-20

Salma. 2014. Tingkat Pengaruh Berbagai Faktor Terhadap Produksi Padi Sawah di Kecamatan Ponrang Selatan kabuapten Luwu.

Salma 2014. Produktivitas Tanaman Padi Lahan Sawah, http://www.pertanianjatim.go.id). Diakses 06 Januari 2014

Salma 2014.

http://qeyty.blogspot.com/2008/10/fungsi produksi.html. diakses tanggal 07 Januari 2014.

Suhartini. 2010. Modul Perkuliahan III Produksi (Teori, Fungsi, dan Efisiensi). Fakultas Pertanian Universitas Brawijaya. Malang

Salma. 2014: http://id.shvoong.com/writing and speaking/ presenting/ 2061554 pengertian pendapatan /\#ixzz2urdqKsdr diakses tanggal 03 Maret 2014

Salma 2014.http:///pedoman teknis bantuan alat dan mesin pertanian Ditjen prasarana dan sarana pertanian T.A2012 diakses tanggal 03 Maret 2014.

Singgih Santoso. 2000. Latihan SPSS Statistik Parmetik. Gramedia, Jakarta. 
Vol. 04 No. 02

Singgih Santoso dan Tjiptono. 2001. Aplikasi dengan SPSS, Elex Media Komputindo, Jakarta. 